\title{
STAGES OF HUSSERL'S PHILOSOPHY AND INTENTION OF PHENOMENOLOGY
}

\author{
JONKUS DALIUS \\ Prof., Dr., Department of Philosophy \\ at Vytautas Magnus University, 44244 Kaunas, Lithuania. \\ E-mail: phenolt@yahoo.com
}

When discussing Husserl's phenomenology, it is often divided into separate stages which have no internal relationship between them. Husserl's anti-psychologism can be opposed to phenomenological psychology, anti-historicism to unfolding of inter-subjective historical worlds, the concept of phenomenology as strict science to criticism of science from the perspective of transcendental self-experience, though by looking for contradictions, we will see only separate aspects of phenomenology and will not notice the general structure of phenomenology. In order to understand the meaning of Husserl's phenomenology, it is necessary to find the unifying thread connecting different elements and levels of phenomenology. When discussing the genesis of phenomenological philosophy, we should not emphasise differences between separate stages, but understand what relates them. In this article the whole of Husserl's phenomenology was reconstructed following the common intention of phenomenology which I understood as criticism of objectivism and naturalism. This intention can be found at all stages of Husserl's phenomenology.

Key words: phenomenological criticism, transcendental empiricism, criticism of psychologism, transcendental consciousness, inter-subjectivity.

\section{ЭТАПЫ ФИЛОСОФИИ ГУССЕРЛЯ И ИНТЕНЦИЯ ФЕНОМЕНОЛОГИИ}

\section{ИОНКУС ДАЛЮС}

Профессор, доктор, кафедра философии,

Университет Витовта Великого, 44244 Каунас, Литва.

E-mail: phenolt@yahoo.com

Гуссерлевскую феноменологию часто разделяют на отдельные ступени, между которыми нет внутренней связи. Антипсихологизм Гуссерля можно противопоставить феноменологической психологии; антиисторицизм - развёртыванию интерсубъективности исторических миров; понятие феноменологии как строгой науки — критике науки 
с точки зрения трансцендентального опыта самости, хотя в поиске противопоставлений мы увидим только отдельные аспекты феноменологии и не заметим её общую структуру. Для того чтобы понять значение феноменологии Гуссерля, необходимо найти нить, связывающую различные элементы и уровни феноменологии. Говоря о происхождении феноменологической философии, мы не должны делать упор на различиях отдельных ступеней, но необходимо понимать, что их объединяет. В этой статье проводится полная реконструкция гуссерлевской феноменологии согласно общей интенции феноменологии, которую я понимаю как критику объективизма и натурализма. Эту интенцию можно обнаружить на всех ступенях феноменологии Гуссерля.

Ключевые слова: феноменологический критицизм, трансцендентальный эмпиризм, психологический критицизм, трансцендентальное сознание, интерсубъективность.

It is of the essence of phenomenological investigation that they cannot be reviewed summarily but must in each case be rehearsed and repeated anew.

Martin Heidegger (Heidegger, 2011, 26)

\subsection{Specifics of Phenomenological Philosophy}

Phenomenology was not developed right away as one indivisible whole. Husserl was developing phenomenological method step by step, extending the concept of phenomenological method and applying it in new fields at every stage. However, despite differences between separate stages, phenomenology must be understood as the whole. It is not something in itself, therefore, it must be understood as a phenomenon manifested through specific aspects in a specific perspective. In order to understand phenomenology, our own position must be reflected, i. e. to comprehend our own circumstances, our own life situation and the way it reflects decisionmaking through the practical application of phenomenology.

Phenomenology is not just philosophy of mind. It is philosophy of the intentional life. It covers all dimensions of life. Phenomenology explores the participation of consciousness in the cultural, social, historical constitution of the world and the way it constitutes itself as the whole. Phenomenological philosophy is universal. It solves all issues related to human life. Today's postmodern philosophy often speaks about the death of philosophy. Philosophy is understood as a maid of sciences or as one of modern literature genres not committing anyone to anything. Philosophy is reduced to pragmatics of social sciences or is made the history of ideas. All the attempts to disqualify philosophy and to turn it into «weak thinking» do not entice phenomenology. Phenomenological philosophy emphasises the practical aspect of philosophy, though understanding it not as rejection of any theories, but as responsibility for theories and their critical consideration taking into account application possibilities. According to Husserl, philosophers should take responsibility for the humanity in general. Philosophers are understood as some kind of aides of humanity. Who else if not philosophers must criticise nihilistic attitudes existing in various concepts of the biological evolution, when a person is perceived as the scope of biological instincts 
or when he/she is described as a product determined by his/her race or tribe. Phenomenological criticism shows that these theories destroy the possibility of both philosophy and sciences as a person is understood only as a natural fact unable to seek the ideal truth.

Why phenomenology is still relevant? To answer this question, we should remember that not only phenomenological philosophy covers theoretical issues and their solving in connection with practice, but also performs critical and moral functions. Phenomenological philosophy criticises various philosophical and scientific theories by showing the insufficiency of their arguments and by revealing their anti-humanistic nature. In other words, phenomenological criticism emphasises principles of ethical responsibility which are impossible if a person is considered to be an irrational and naturally determined being. Phenomenological criticism shows that many scientific theories about a person are based on facts whose selection implies value assumptions. However, these assumptions themselves mostly remain non-thought-out within the framework of scientific theories. Therefore, scientific theories are presented as a reflection of the «objective» reality, completely regardless of the moral stand of the scientist. When seeking objectivity, such concealment of moral assumptions acquires the legitimised scientific nature.

Husserl's phenomenology initiated the renewal of philosophy based on the call «to return to things». Despite all internal disagreements and mutual criticism, most phenomenologists of the XX century tried to implement this principle in one or another way. Martin Heidegger, Jose Ortega y Gasset, Eugen Fink, Emmanuel Levinas, Merleau-Ponty, Jean-Pol Sartre and other phenomenologists tried to return philosophy to things, i. e. to consider things not as they are but as they exist and are manifested in the human life. Return to things means the radical renewal of philosophy as it rejects naivety of school philosophy and sciences used to postulate self-existence of the objective world forgetting own place in this world. Scholastic verbosity, disputes over terms and multiplication of texts about texts made once again try to start philosophy from the beginning, i. e. to encourage philosophers to think considering the past. But why do we need experience when we are talking about things? In order to talk about things, it is necessary to analyse how they are given in experience. It is naive to believe that things are merely revealed without contacting them. Husserl does not cease encouraging to think independently by ascertaining and checking things in most obvious personal experience. Though, this personalism of experience must be reflected in order to reveal and describe structures of consciousness without which considering the given of things would be impossible at all. Tomas Sodeika describing Husserl's concept of «pure consciousness» states: «Thus, by analysing consciousness a phenomenologist explores it not as an empirical fact or a scope of facts, but as a certain ideal structure, the necessary and universal essence of consciousness repeated in every real situation, in every real act. The consciousness-oriented look of a phenomenologist sees not certain mental experience in it (a specific person, a specific situation), but only essential, necessary structures of that experience, a kind of ideal "frame" of it. A phenomenologist tries to distinguish and describe moments of that experience constituting the essence of any experience, making experience what it is. For example, when examining how a physical object is observed, a phenomenologist is interested neither in the social status of an observer, nor in his/her education, age, and individual mental parameters. A phenomenologist 
cares neither about a specific situation during which the observation takes place, nor even about the object of observation; the only goal here is to identify the moments making the state of consciousness being explored the "observation of a physical object" (Sodeika, 1981, 66). I agree with Tomas Sodeika that a phenomenologist explores consciousness not as an empirical fact or a scope of facts and that a phenomenologist tries to distinguish and describe structures of experiences, though I disagree that a phenomenologist cares neither about a specific situation, nor about the object of observation. The description of pure consciousness provided by Tomas Sodeika could probably fit the early stage of Husserl's phenomenology, however, when developing the phenomenological method, Husserl was increasingly emphasising the specific subject and the self-analysis of its experience, without which the phenomenological approach to things would be impossible. Here, we are dealing with the specifics of phenomenological exploration of consciousness, with the paradox of consciousness experiencing the world. Let us examine an example. Here I see a table. It is the table I work at. It is loaded with books and papers and it has a computer and a keyboard on it which I use to write my text. In order to understand the meaning of the table as a physical object, I have to focus on how it is given in my perception. Perceiving the table as a physical object, I exclude its validity as a tool having a cultural meaning and serving the realisation of my specific goals. Focusing on the description of the table as a physical object, I have to reflect on how it is given in my specific perception, in this case, how it is seen. So, how do I see the table as a physical object? I see it the way it is given to me from its one side. I see the table from a specific perspective and due to it the table is given from its certain aspect. I do not see the whole table. I see the table top and what is on it, but I do not see what is under and behind it. Thus, limiting myself to the observation of the table as a physical object and reflection of this observation, I can judge that the physical object should necessarily be manifested in a specific perspective of perception as being given from its one or another aspect. There is no perspective of visual perception which could give me the whole table, with all possible aspects of its manifestation. In this sense, even the divine vision, so far as it is directed to the object as a physical object, should obey these laws of bodily perception perspective without which the vision of the physical object as being spatially extended would be impossible. These reflections of perception reveal the table's consciousness structure. The table can be understood as a physical object only when we perform certain exclusion of other meanings of the table, when we focus on how the table is manifested through specific aspects of its physical being in a specific observation. The table's consciousness covers both specific acts of consciousness and ways of the table's physical given. The initial discovery of static phenomenology is that consciousness of the table as a physical phenomenon can be described by correlating acts of consciousness and objects of consciousness. The former are intentionally directed to the given of a certain object, the latter determine possibilities of accessing them by the way of their given. At this level, a specific observation situation and my personal perception would be seemingly left excluded but this exclusion, as we shall see, postpones the implied possibilities rather than destroys them. I can ignore the table as a tool for my practical activities mediating in relations with others, i. e. parenthesize its cultural and social meaning. I can ignore temporal aspects of the table's given. I can ignore the way my previously acquired passive schemes of perceiving the table 
as a physical object act in my perception, the way my bodily movements participate in this perception.

Still, how do I still realise I see the table, and not the table top? My vision of the table implies other vision possibilities, other perspectives perceived along with relevant aspects of the table's given. Husserl writes:

I can let my attention wander away from the writing table which was just now seen and noticed, out through the unseen parts of the room which are behind my back, to the verandah, into the garden, to the children in the arbour, etc., to all the Objects I directly "know of" as being there and here in the surroundings of which there is also consciousness - a "knowing of them" which involves no conceptual thinking and which changes into a clear intuiting only with the advertence of attention, and even then only partially and for the most part very imperfectly (Husserl, 1983, 52).

The perception of every object implies a certain perception horizon which Husserl refers to here as «co-supposed» surroundings. This supposition of surroundings which is directly implicated in my relevant observation of an object was later called the perception horizon by Husserl. Thus, what remains unclearly implied is also perceived, rather than made up or thought up, in every relevant perception. The perception does not end with explication of the relevant given. Every perception requires extensions in another one, every aspect of a perceived object shows another possibility of its perception which can be implemented through the extension of the relevant one. The modification of the classical issue of transcendence lies in the very peculiarity of consciousness intentionality. Every perception of the present implies overstepping it, i. e. transcendence as an active or passive experience of otherness. In this case, what happens to phenomenology seeking to describe the correlation between consciousness and the world in separate acts of consciousness? Phenomenology becomes a utopian project as a phenomenologist seeks to implement the endless task, though he/she perceives his/her performance as partial and imperfect. Just like none of acts of consciousness can be considered fully completed as it requires extension in others, none of descriptions can be considered perfectly complete...

Returning to the example with the table, let us ask once again: can the sensory-empirical given of the table provide the possibility to see the universal essence of the table from one aspect of it? From the view of empiricism, our answer would be negative: empirical impressions do not ensure insight into essences. In this respect, we should always see the table from one or another side only, and relationship between separate aspects of the table would be random associations only. Husserl states the opposite - insight in the table's essence is possible and it is shown by the analysis of pure experience structures. However, when describing pure, i. e. transcendental, structures of consciousness, Husserl does not exclude the empirical dimension. What relates different table profiles is given in the way the table is manifested and experienced. Husserl does not oppose empirical and transcendental consciousness as two opposites. He understands them as two sides of the same coin. Thereby, it changes the traditional concept of transcendental consciousness which equated transcendental consciousness with pure one, i. e. 
with the consciousness elevated above any empirical circumstances. Husserl's phenomenology cannot be limited to research of pure consciousness and its structures only, as Husserl finds this consciousness in the empirical given itself. Today, Husserl's phenomenology is proposed to be called transcendental empiricism. According to Natalie Depraz, the concept of transcendental empiricism transforms the paradigm of philosophy and leads away from pragmatics to hermeneutics (See (Depraz, 2003, 94)). In summary, it can be stated that the phenomenological description of the table cannot be satisfied with the description of pure structures of the table as an empirical phenomenon or its perception as a physical object. This description must be expanded so as to cover all above-mentioned aspects which remained implicit horizons only. Just like the table cannot be perceived by limiting its perception by a separate act of seeing in which it is given as a physical object from one side of it, so the phenomenological project could not be limited by the explication of pure structures of consciousness, though it was expanded by including previously non-thought-out horizons. Husserl as if shows by his book title «Ideas Pertaining to a Pure Phenomenology and to a Phenomenological Philosophy» that pure phenomenology must become phenomenological philosophy, i. e. it must proceed from the description of pure structures of consciousness to the reflection of experiences of the world with all its horizons. The concretization and application of phenomenology in various dimensions is often called existential phenomenology, hermeneutic phenomenology or even post-phenomenology, though it does not change the essence of the matter as the same core of phenomenology appears in all variants of phenomenology.

Why is Husserl's concept of phenomenology misunderstood and often identified with Enlightenment rationalism, subjective irrationalism or psychological introspectivism? Much misunderstanding emerges from specifics of Husserl's philosophizing. The first thing that strikes one's eyes is the outdated terminology of the founder of phenomenology. It is completely permeated with the spirit of the XIX century. The modern reader should parenthesize this language of the philosopher and should not draw his/her attention to it, but look at the things being discussed. Thus, the mind, rationalism, idealism, science, spirit, theory and practice are concepts referring to realities other than those peculiar to philosophy of the XIX century. Secondly, phenomenological concepts are understood in terms of phenomenology as a whole only. And this whole can hardly be covered as, in addition to several published Husserl's books, there are over 50000 manuscript pages and texts of lectures delivered by him which have not been completely published yet. Thirdly, phenomenological concepts are not only a part of the structure of phenomenological theory, but they also perform a certain practical function, i. e. refer to operations which must be mastered, turned into own usual movement by every phenomenologist. Therefore, phenomenology can be understood only phenomenologically — by learning it as a certain experience rather than looking from the outside as if it was an object in itself. Phenomenology is understood by constituting its meaning, like the meaning of scissors is understood by learning how they work.

\subsection{Stages of Husserl's Phenomenology}

When discussing Husserl's phenomenology, it is often divided into separate stages which 
have no internal relationship between them. Husserl's anti-psychologism can be opposed to phenomenological psychology, anti-historicism to unfolding of inter-subjective historical worlds, the concept of phenomenology as strict science to criticism of science from the perspective of transcendental self-experience, though by looking for contradictions, we will see only separate aspects of phenomenology and will not notice the general structure of phenomenology. In order to understand the meaning of Husserl's phenomenology, it is necessary to find the unifying thread connecting different elements and levels of phenomenology. When discussing the genesis of phenomenological philosophy, we should not emphasise differences of separate stages, but understand what relates them. Is it possible to find the common intention of Husserl's phenomenology? Is that intention continued in works of other phenomenologists, does every phenomenologist have to start everything from the beginning? Yes and no. I think there is a fundamental intention of phenomenology. However, it does not mean that a phenomenologist must uphold the phenomenological tradition as the authority-based continuity. A phenomenologist must start from the beginning every time and actualize the evolving tradition without avoiding interruptions. Husserl called this renewal and orientation of the approach epoche. The former name refers to an operation which not only allows to stop inertia of the evolving movement, but also enables to perform the reduction, i.e. to return to fundamental experiences and the world given in them. The most important intention of phenomenology is the resistance to one-sidedness of objectivistic and naturalistic thinking. Husserl formulates this intention in his own criticism of psychologism and clearly emphasises in his later works. The concept of fundamental intention enables to see the structure of phenomenological theory and master its practical functions allowing to solve not only theoretical issues, but also tasks of our life. ${ }^{1}$

This article reconstructed the whole of Husserl's phenomenology following the common intention of phenomenology which I understood as criticism of objectivism and naturalism. This intention can be found at all stages of Husserl's phenomenology. I distinguish three stages of Husserl's phenomenology. Every one of them is related to one of three universities where the founder of phenomenology used to teach and to three books summarizing achievements of every separate stage. The first phenomenological book by Husserl is the two volumes of «Logical Investigations» (1900-1901) crowning the first stage of phenomenology related to the University of Halle. The second book is «Ideas Pertaining to a Pure Phenomenology and to a Phenomenological Philosophy» (1913), it completes the second stage related to the University of Göttingen. The third stage, which begins with World War I and continues until the death of Husserl, is related to the University of Freiburg and given meaning in last book «The Crisis of European Sciences» (partly published in 1936).

\subsection{First Stage of Husserl's Phenomenology \\ Criticism of Psychologism, Criticism of Historicism and Issue of Subject}

Phenomenology begins as criticism of psychologism expounded in the first volume of «Logical Investigations». Psychologism sought to justify science and scientific activities

1 For more details about the intention of Husserl's phenomenology, see San Martin, 1994. 
by the psychological analysis. It was believed that the cognition of psychological laws would allow to explain the mechanism of the appearance of truth, and the revelation of the actual-psychological structure of the subject would solve all the issues of cognition. Such concepts basically naturalized concepts of consciousness and a person. Describing the position of psychologism, Algis Mickūnas notes:

The study of mental activities was reduced to descriptions of empirically describable processes; those aspects of mind not open to such analysis were deemed merely "subjective" and of no scientific importance. The effect of this shift in method was to describe the total human subject as just another "thing" in nature. Man was interpreted as another "object" to be investigated by the same methods used in the physical sciences. This signaled a kind of radical reductionism in which all human functions were reduced to physically observable characteristics (Mickūnas, Stewart, 1990, 17-18).

Psychologism basically naturalized processes of consciousness. Husserl harshly criticised such an attitude by showing that psychologism inevitably leads to relativism and scepticism. Assuming that all the scientific truths are a product of some or another mental structure, the contingency of truths would have to be recognized. In this case, different mental subjects could have different truths, different laws of logic and mathematics. Of course, we could give it up and justify ourselves that it applies to mathematics and logic only. However, Husserl, even though he speaks about logic, sees here the essential issue of the mind status. Is the mind contingent, can it be reduced to the actual structure of mental subject's functioning? If so, cease to be valid are both mathematical-logical truths and ethical-legal norms. If there is no rational non-contingent subject, then there is neither universal norms, nor values.

Why is solving of the psychologism issue related to ethical relativism and nihilism? In order to put more emphasis on the dilemma faced by Husserl, I am going to provide the example of Ortega y Gasset, as in his book «The Modern Theme» (1922) we find formulated alternatives to the solution of the rationality issue. When defining the main theme of our epoch, Ortega asks: «How can we admit truth, which is complete in itself and invariable, to the society of human vitality, which is essentially mutable and varies from individual to individual, from race to race, and from period to period? If we wish to keep to living history and pursue its suggestive undulations we must renounce the supposition that truth is ascertainable by man. $<\ldots>>$ "The" truth, then, does not exist: there are only truths "relative" to the frame of mind of the person considering the matter. Such is the relativist theory. But this renunciation of truth, so lightly undertaken by the relativist theory, is a more difficult business than may at first appears. It is claimed that by this means a lofty impartiality of outlook is obtained upon the multiplicity of historical phenomena; but what is the price? In the first place, if truth does not exist, relativism cannot take itself seriously. Secondly, belief in truth is a deeply-rooted foundation of human life; if we remove it, life is converted into an illusion and an absurdity. The operation of removal is itself devoid of common sense and 
philosophic value. Relativism is, in the long run, scepticism and scepticism, when its justification is that it opposes all speculative theory, is in itself a theory of suicidal character» (Ortega y Gasset, 1961, 28-29).

Another, the opposite position - rationalism which in Ortega's judgment represents Descartes' philosophy:

The enthusiasm of Descartes for the constructions of reason led him to effect a complete inversion of the perspective natural to mankind. The immediate and evident world we observe with our eyes, touch with our hands, listen to with our ears, is composed of qualities: colours, resistances, sounds and so on. This is the world in which man has always lived and always will live. But reason is not capable of dealing with qualities. $<\ldots>$ With heroic audacity Descartes decides that the true world is the quantitative, the geometrical: the other the qualitative and immediate world that surrounds us in all the plenitude of its beauty and suggestive force, is dismissed, and assumed to be, in a way, illusory (Ortega y Gasset, 1961, 32).

The alternative defined by Ortega is simple: if we can accept neither relativism denying the principles of rationality, nor rationalism rejecting the spontaneity of life and requiring to look at the world with eyes of the «pure subject», then only way out for us is to find or create rationality in life itself. The concept of the «vital reason» or «reason with life as its foundation» by Ortega y Gasset chooses the middle way. The reason is not scattered in the contingency of historical, cultural situations, though, on the other hand, it is not identified with the pure mind. Rationality is found not by denying experiences, but by revealing structures existing in their relationships. When looking for rationality in individual and spontaneous life, Ortega formulates one of the most important theses of his philosophy as follows: «I am I and my circumstances». Ortega's concept of the mind coincides with the fundamental intention of phenomenology in terms of its meaning and avoids traps of both relativism and one-sided rationalism.

Criticism of psychologism and later criticism of historicism expose the issue of the subject and widely-understood rationalism. What is that rationally-living and science-and-history-creating subject? The question is raised not only about assumptions of scientific activities, but also of any other inter-subjectively meaningful activities. Therefore, origins of Husserl's further ethical, historical and cultural philosophical reflections can be found in his very first phenomenological works.

\subsection{Intentionality of Consciousness and Principle of Correlation}

Husserl is often reproached for being the philosopher of «consciousness». In fact, the issue of consciousness is one of the most important themes of phenomenological meditations. However, we should bear in mind that Husserl perceives consciousness phenomenologically and rejects naturalistic and substantialistic concepts of consciousness. Consciousness is perceived not as a substance, but as an activity and self-realization. Husserl rejects the 
concept of empirical consciousness according to which consciousness is like a clean table with external objects leaving their marks by affecting our senses. He also rejects the rationalist concept of consciousness as an empty pot which can be filled with many images. The concept of phenomenological consciousness is based on the principle of correlation. The intentional analysis must be based on the life description of consciousness, but experiences of consciousness cannot be described without their relationship with the things being experienced. Since consciousness is always «consciousness-about», then when describing the life of consciousness I should describe not consciousness as it is in itself, but consciousness as it is directed towards certain things. Love is the love of someone. I cannot love «nothing». A phenomenologist is interested in not just consciousness, but in consciousness of the world. A phenomenologist must turn to experience and reflect what is given in experience and how it is given in experience in relation to specific acts of consciousness. This return of seemingly independent objects to acts constituting them is nothing more than the intentional analysis of consciousness. Intentionality of consciousness means that all the acts and experiences of consciousness are directed towards certain objects, and these objects, in their turn, are related to the performance of experiences establishing or supporting them. Consciousness cannot be empty or about nothing, as in this case there would simply be no consciousness or it would be unconscious. Thus, the life description of consciousness implies the description of not only acts of consciousness, but also of things given in these acts. I can analyse acts of love, hatred, evaluation, calculation and loved, hated, evaluated or calculated objects given in them. However, not only acts of consciousness are related to what they are directed to, but also all analysed objects can be described only as given in certain experiences from this standpoint. I can describe love for a particular person and this love will be directed to him/ her. On the other hand, this beloved person will be described as beloved only in relation to these particular experiences. Moreover, I can describe love for an imagined princess or a movie hero, though these objects of love will also be described not as real, but as imagined or ideal objects, i. e. given in corresponding acts. The intentional analysis covers all relevant and potential objects of consciousness in their relation to corresponding experiences.

Intentionality of consciousness means that consciousness must be analysed abstaining from metaphysical concepts of the nature of consciousness. It is more important not to clarify the nature of consciousness or localize where exactly it is, but to describe how consciousness is experienced and how various objects are manifested in its experiences. This requirement allows to overcome the opposition between consciousness and the world. Real, imagined, ideal objects will be described only to the extent they are given or manifested in consciousness. In this sense, phenomenology must describe the intentional life of consciousness or, in other words, phenomena. Therefore, the principle of intentionality of consciousness is the most important principle of phenomenology, as it was understood by Husserl at the first stage.

Another, no less important, feature of intentionality of consciousness is that intentionality of consciousness can be described only from the experience of experiences themselves and their mutual relationship. Let us have an example: reading these words, you, the reader, always perceive something. Something can be read only as something meaningful. Thus, a 
certain meaningful object, word or sentence written by me is implied in your act of reading which you seek to understand by reading it. Understanding of words and sentences means understanding of what they tell you. Thus, reading as an intentional act will be directed to certain meanings which will be telling you something as their reader, though they are written by me. Reading experience is inter-subjective. To read meaningfully is to actualize experiences of others as if of your own. When reading words written by me, you should actualize my writing experience or, in other words, sedimentations of my experience in writing. In addition to this, it should be added that the very act of reading is not functioning of the pure mind, but experience of an embodied person. Reading, like listening or touching, relates what is experienced with the very act of experiencing. Therefore, intentionality of reading experience is not explicated in any other way than from the first-person perspective. You will not understand reading experience and what you experience in it if you try to explain it as the empirical text-brain interaction or as the influence of letters on the eyes retina. In order to understand how objects are manifested and become significant in their specific experiences when reading, touching or listening to them, you should understand them as given in personal experience. The relationship between intentional objects and intentional experiences becomes clear only when you realize it as your own inter-subjective experience being experienced. You must understand not what is written here, but what the written text has in mind. Consciousness cannot be described from the side, i.e. by reducing it to the empirical interaction of objects or to physical and physiological processes, as the essential feature of consciousness - intentionality - is lost every time in such reductions.

\subsection{Second Stage of Husserl's Phenomenology Return to TRANSCENDENTAL SUbJeCTIVITY}

With the first volume of «Logical Investigations» criticising psychologism and naturalism, Husserl justifies the existence of idealness independent of the contingent subject. However, these ideal objects can be perceived only in acts of consciousness described by Husserl in the second volume of «Logical Investigations». Phenomenology describes acts of consciousness and objects of consciousness correlated with these acts. The question arises inevitably: whose consciousness is it? What is the subject of these acts of consciousness? Trying to answer these questions, Husserl formulates the concept of transcendental subjectivity directly related to the concept of reduction and epoche.

Phenomenological reduction, which is one of the most important themes of Husserl's «Ideas Pertaining to a Pure Phenomenology and to a Phenomenological Philosophy», caused much controversy and discussions among phenomenologists. Many followers of Husserl treated the transcendental reduction as the direct path to solipsism and idealism and, therefore, believed that Husserl refused his former realism entrenched in «Logical Investigations». Husserl himself staunchly defended the methodological necessity. According to him, those who did not understand the essence of the transcendental reduction did not understand the phenomenological method as well.

What is the point of this reduction? Reduction, as a return to the transcendental subject, 
is already implied in criticism of psychologism. It makes clear that the subject of science cannot be a random subject constituted by psychological structures and historical circumstances. One conclusion is likely - such a transcendental subject can only be the subject of rationality. But how to reach it? Will pure «ego» abstracted from contingent circumstances of the world be such subject searched for? Husserl shows a different path, the path of not rational structures, but of the practical self-realization. Therefore, reduction becomes a symbol of openness of practical-theoretical transcendental subjectivity.

First of all, the act of reduction is associated with epoche. Since intentional acts of consciousness are related to human life as the whole, Husserl points out that life can be described objectively as given in the world or subjectively as an experience. The phenomenological description must exclude the objective perspective and focus on the subjective one. This is the primary meaning of epoche. For example, let us pay attention not to objective, but to subjective perception of time. Time is perceived in one way when measured in hours, days, calendar years, position of the sun and planets, and it is perceived in a different way while boringly waiting for a delayed bus or when a beloved person does not appear after a long separation.

The movement of transcendental reduction is the change in attitudes. Husserl notes that epoche and reduction must be applied with regard to the natural attitude. The natural attitude is the normal way of person's being in the world when we attribute all relevant and possible objects of our experience to the real world, and all real objects prove my own being among them as one more chain of this world. When applying epoche with regard to the natural attitude, the affirmation of the objective world is parenthesized. Reflection through which I re-orient my attention away from real things to things in experience neutralizes my relationship with the object. Reflection always establishes a distance to an object, though, on the other hand, it allows to concentrate on experience itself. When remembering, I think about a person I loved, I can be neutral with regard to him/her asking why he/she, and not someone else, maybe he/she did not exist at all, though thanks to all that I can direct my attention towards love experienced by me (the question is, was it love?), I can describe my experiences remaining neutral with regard to the person I loved and to my real or imaginary love. However, when I was in love, I could not think of anything else but her and I had absolutely no idea what was happening to me.

Thus, there are two attitudes: natural, directed to something/someone in the world and phenomenological, directed to experiencing of experience itself. Epoche neutralizes and suspends the belief in the world being natural. So, what comes out of all of this? Having lost the natural world, I am left with experience of the world and the parenthesized, neutralized world of experience. At this level, phenomenology is understood as the description of experiencing of experience and what is given, to the extent given in this experience. Husserl says: «Let us exclude all apprehendings which reach out beyond what is given intuitionally» (Husserl, 1983, 155).

Having specified the concept of phenomenological consciousness, we can state that most critics of Husserl identifying his philosophy with Kant-type idealism miss the point. Phenomenology actually speaks about the transcendental subject which the necessity to reject abso- 
lute relativism leads to. However, transcendental consciousness is not the pure subject as understood by classical philosophy. Transcendental consciousness opens in a specific empirical situation, it is realized in a certain journey which radically changes the perception perspective and during which the discoveries of this change are reflected. The question is: how to find the proper path to transcendental consciousness, and maybe there is no need for any journey, as we already have that transcendental consciousness, but we cannot realize that?

When thinking over Descartes' philosophy, Merab Mamardashvili notes that experience of journeys of the latter can be described as symbolic reduction:

As I said, Descartes travelled a lot, though he was a strange traveller: he did not write a single book, a single page which could be traveller's notes or what the Germans called Reisebuch - a travel diary. Descartes does not even say a single word about what he saw, what happened to him. Obviously, these were symbolic journeys, a little can be found about them only through his spiritual state. By his life he demonstrated what started to be called reduction in the XX century (reduction is known to be as parenthesizing of the natural or objective world, peering into a phenomenon). Here, he describes the way he perceives or experiences Holland, quoted from memory: "I feel so good among people of this nation whose language I do not understand, so I can examine people in the crowd and between houses as elements of a still life. Their language is no more significant for me than birds signing. I am alone among these people working hard like bees." Of course, this should be considered a symbol. Let us assume, Descartes examines some Dutch city, he looks at it as a still life, not knowing the meaning of what is presented to him or what he sees, his state is reduced. For example, he sees a horse pulling a carriage, but he does not know that the horse (in terms of its utility) is thrust, and the wheel is the main part of the carriage, etc. He looks at all of it as if with the look of a Martian. Why? Because, according the philosophy he lived by, one can be born and can stay only having broken off the so-called organic or natural links established independently of oneself. Descartes is the real participant of his life rather than living in wonderful Touraine which can be hardly compared with Holland, in the fabulously beautiful heart of France (it would seem, what else does such a "cissy" need), — but no, he does not live there. But if he had, he would have lived like in a cocoon, under the pressure of an atmospheric column made of provided, and not of individually (and not from oneself) devised thinking culture, between organic, self-weaving links. To be more precise - connections, "bands". And he as if physically models his aspiration for breaking off these "pre-renatian" links, models by the organised landscape of life - he lives in Holland, like in some still life, landscape which he has not internal relations, no common successive fabric with, and even if they appear, then only those created by himself (Mamardashvili, 1993, 27-28).

Mamardashvili understands a journey as the analogue of reduction. The most important thing is a certain state achieved by neutralizing natural links. Reduction is equalled to the radical change of the standpoint or to the inquiring look when meanings of things are no 
longer self-evident. When travelling, a person can achieve such a state spontaneously. Such journeys are not tourist hunting for impressions, but a symbolic journey to the self, during which experience of the world is re-discovered. Therefore, Descartes offers to «...no longer to seek any other science than that of myself and of the great book of life...»

\subsection{Phenomenological Reduction and Phenomenological Practice}

Husserl presents the phenomenological reduction as the method of thematizing transcendental consciousness. In the first volume of ideas about pure phenomenology, he describes reduction as the exclusion of the general thesis. However, this description is not very clear. What is the general thesis and what does its exclusion stand for? When interpreting the meaning of the phenomenological reduction, I would like to draw attention to the fact that the phenomenological reduction can be understood in two ways. First, the phenomenological reduction can be identified with epoche as the negative and sceptical action in respect of the real world. Then, phenomenological reduction is understood as the exclusion of the real or objective world and suspension of all decisions about such world. This understanding of the phenomenological reduction results in focusing on the interiority of consciousness and reflection of various acts of experience. In this case, the phenomenological reduction is something like Cartesian doubt whose purpose is to discover the absolutely undoubted basis for all sciences. By following the path of Cartesian doubt, phenomenology discovers consciousness as the only and most obvious basis of knowledge. However, in my opinion, the phenomenological reduction cannot be identified with Cartesian doubt and search for the undoubted basis. Phenomenological reduction contains not only the theoretically formulated task of substantiation of sciences, but also the practical result obtained by the radical change of attitudes. The second version of the phenomenological reduction emphasises not that the validity of the real world must be excluded, but what is experienced when neutralizing the self-evident primacy of the natural world in respect of experience itself. First of all, attention should be drawn to the fact that epoche means stopping of inertia of consciousness. We should refrain from the postulation of the natural world, as if it determines my every perception by itself or every experience is explicated as a reflection of this world. In this case, refraining is not the sceptical denial of the natural world, but its experience in the light of «amazement» as given in specific experiences. Epoche is not only the negative exclusion, but also positive orientation. By changing the world outlook, we do not lose the world itself. It is discovered as the world of experience. Epoche is refraining from the postulation of the natural world and this negative refraining turns into positive refraining by experience itself and what is given in it. Husserl emphasises that the purpose of epoche is not negative: «But our purpose is to discover a new scientific domain, one that is to be gained by the method of parenthesizing...» (Husserl, 1983, 60). Therefore, epoche can be equalled neither to sophistic denial of the world, nor to sceptical doubt of its existence. First of all, epoche should parenthesize scientific statements understood as a reflection of the reality in itself:

Thus I exclude all sciences relating to this natural world no matter how firmly they 
stand there for me, no matter how much I admire them, no matter how little I think of making even the least objection to them; I make absolutely no use of the things posited in them. Nor do I make my own a single one of the propositions belonging to <those sciences $>$, even though it would be perfectly evident; none is accepted by me; none gives me a foundation - let this be well noted: as long as it is understood as it is presented in one of those sciences as a truth about actualities of this world (Husserl, 1983, 61-62).

Is such parenthesizing of scientific statements about natural actualities of the world possible? Is it possible to refrain from scientific statements explaining the world as the natural causal chain, and scientific experience is presented as the only actuality of the world? It should be noted that Husserl does not offer to reject the scientific approach to actualities. He offers not to accept scientific statements as self-evident and once and for all explaining actualities of the world. By parenthesizing the absolute validity of these statements, we should not rely on them as long as scientific statements are understood as the truth of actualities of the world and their assumptions are not reflected. In other words, in order to understand what love is, I should, first of all, refrain from, say, biological or physiological interpretations of love. As if love is such an instinct ensuring the perpetuation and reproduction or that love is a certain chemical reaction in my brain. Refraining from such reasoning is required to turn towards the phenomenon of love and to reflect its experience.

Every beginner phenomenologist seeking to master the phenomenological method faces the necessity to consider the phenomenological reduction. Despite many texts in which Husserl describes this phenomenological concept, along with the methodical operation, the reader faces a series of challenges. These are problems related to the practical implementation of phenomenology. The thing is that phenomenology highlights the practical nature peculiar to philosophy clearly. Describing the phenomenological reduction, Husserl observes: «Precisely by this < practical consciousness> we protect ourselves methodically against these confusions so deeply rooted in us as born dogmatists; in no other way could we avoid them» (Husserl, 1983, 141). Therefore, Husserl's phenomenological texts are not the presentation of the objective world outlook, but the thematization of the own path travelled (experience).

It can be said that the question faced by the beginner phenomenologist is the same question faced by the beginner philosopher. How to master philosophy? How to start philosophizing? In general, the initial understanding, as well as the birth of an idea, is the paradox of primordiality whose experience phenomenology always relies on. But does experience of primordiality coincide with the absolute and undoubted basis of knowledge which could be relied on as own property?

Returning to Husserl's texts as a whole, we can state that we are not going to find in any text a definitive answer as to what phenomenology is, we are not going to find in any text a definitive description of the phenomenological reduction, as none of definitions included in texts is going to helps us carry out the phenomenological reduction and see things in a new way (phenomenologically). Does it mean that phenomenological texts, as well as 
texts about phenomenology, are not worth reading at all as they cannot indicate the practical understanding of phenomenology in us? Phenomenology can be understood only from the phenomenological perspective. In other words, phenomenology is understood only through practical mastering of a certain (other than usual) way of «seeing». It can be done only by practicing phenomenology. In short, the beginner phenomenologist has to already «be experienced». But how to learn swimming without getting into the water? Aristotle speaks about similar things in the «Nicomachean Ethics» reflecting on practical subtleties of teaching philosophy:

Now each man judges well the things he knows... Hence, a young man is not a proper hearer of lectures on political science. For he is inexperienced in the actions that occur in life, but its discussions start from these and are about these. And, further, since he tends to follow his passions, his study will be vain and unprofitable, because the end aimed at is not knowledge but action (1095 a).

Many texts on Husserl's phenomenology should be read not as treatises on theoretical philosophy, but as meditative exercises. It means that while reading, I should try again and again to perform operations through which I (here, I mean not only myself, but also you, the reader) can describe my experience and what is given in it. However, such meditations should not be limited to solving of theoretical and scientific issues only; they should change my entire life. In other words, reading must be comprehensible, turning into the action of experiencing.

\subsection{Project of Critical Phenomenology and Practice of Description}

So far I have been emphasising the practical nature of phenomenology as the strength of phenomenology is its practical application. It does not mean that the phenomenological theory is unnecessary; this theory must be motivated by practice itself. Meanwhile, Husserl often fails to find appropriate means of expression for his developed phenomenological practice. San Martin refers to this contradiction between phenomenological theory and practice as to two different stages of transcendental phenomenology: descriptive, related to the practice of description and critical, related to mind criticism (San Martin, 1987, 274).

Which is more important, to discover the undoubted basis of sciences or just to describe experiences, their structures and what is given in experiences? The transcendental reduction is a return to the field of transcendental subjectivity whose description is the main task of phenomenology, though carrying out of the transcendental reduction is motivated by the endeavour of absolute cognition. In other words, in the first volume of «Ideas Pertaining to a Pure Phenomenology» Husserl links the necessity of the transcendental reduction with the Cartesian paradigm of absolutely grounded knowledge. Therefore, Husserl's philosophy highlights the difference between the phenomenological theory and practice. The phenomenological description is a practical action which partially overlaps with Husserl's endeavour to justify science by finding the absolute basis for it. This contradictions between phenomenology as mind criticism and phenomenology as the practice of description 
is solved through the development of phenomenology when a phenomenologist refuses the initial motivation which he initiated the transcendental reduction for: «Any theory of the phenomenological reduction can be separated from the motivation of the beginner philosopher» (Husserl, 1959, 171).

Does not the emphasis on the phenomenological practice mean that the concept of mind must be also abandoned along with the aspiration for the validity of the absolute cognition? In my opinion, when reflecting subjectivity as the place of discovering the truth and obviousness, a phenomenologist should not reject the mind completely, but turn it into the mind of life, practice-motivated discourse. In other words, when rejecting Cartesian rationalism, it is not necessary to abandon the rationality discovered in the everyday world around us. Experience motivates the practice of description in which the rationality of experience structures and what is given in experience is revealed. Thus, the description turns into the cultivation of new ways of experience:

Corresponding to the process of live experience is the way of its discovery - the description which is understood not as the pure inventory of "consciousness facts", but as the dissemination of meaning. The successful description discovers something through words; it allows us to see what we would not be able to see otherwise (Waldenfels, 1999, 147).

The description of the «dissemination of meaning of experience» is peculiar not only to phenomenological philosophy, but also to literature. Therefore, it is possible to speak about parallels between phenomenological and literary descriptions.

\subsection{Overcoming Transcendence and Representation}

Discussion of the phenomenological reduction led us to the split between phenomenological practice and theory. But what happens to the mind issue sought to be solved. The practical, life meaning of the mind can be understood only when looking deeper into the anti-modernist intention of phenomenology. Husserl seeks to avoid consequences of Cartesian dualism: dualism of body and mind, world and soul, exteriority and interiority, phenomenon and thing in itself. The contradiction between the universality and individuality is rejected, as the universality is found in individual experience. In the very first part Essence and Eidetic Cognition of «Ideas» Husserl emphasises that the world is given to us all the time not in the form of pure facts, but as the world of essentially classified facts. This presupposes that the rationality and meaning lie in the immediate environment, in everyday experience. It should be remembered again and again that what mostly matters in phenomenology is not the opposition of the fact and essence, the outside and inside, but the intuition of correlation between the world and consciousness.

Can epoche overcome the duality of the world and consciousness? Let us return to the concept of reduction and what remains after the reduction. After the reduction, I stay with my experience and the neutralized world given in that experience, which means that the subjective perception (representation) of the world derives from the existing world. In other 
words, such understanding of the reduction is nothing more than the abstraction of mental life from the real world. If epoche is parenthesizing of the objective world allowing to focus on experiencing subjective experience, then this reduction is insufficient, as having focused on mental life, the real world beyond mental life is presupposed. Thereby, we get the classical division between the real world and the subjective representation of the world. Thus, the reduction described above was the psychological reduction rather than the transcendental reduction. Husserl states the difference between psychological and transcendental reduction in Paragraph 11 of the «Cartesian Meditations» by saying that after the transcendental phenomenological reduction

no longer am I the man who, in natural self-experience, finds himself as a man and who, with the abstractive restriction to the pure contents of "internal" or purely psychological self-experience, finds his own pure "mens sive animus sive intellectus"; nor am I the separately considered psyche itself (Husserl, 1977, 25).

During the reduction, the affinity of the natural self-experience and the psychological self-experience becomes apparent, as the latter focuses on the closed soul, which implies getting abstracted from the world, society and culture which this soul exists in. By going deeper into the issue of reduction Husserl discovers that the performance of the reduction should destroy any transcendence of the real or objective world. The meaning and existential status of objectivity and transcendence must be discovered in acts of the transcendental self-experience:

By phenomenological epoche I reduce my natural human Ego and my psychic life the realm of my psychological self-experience - to my transcendental-phenomenological Ego, the realm of transcendental-phenomenological self-experience. The objective world, the world that exists for me, that always has and always will exist for me, the only world that ever can exist for me - this world, with all its Objects, I said, derives its whole sense and its existential status, which it has for me, from me myself, from me as the transcendental Ego, the Ego who comes to the fore only with transcendental-phenomenological epoche (Husserl, 1977, 26).

Thus, speaking about parenthesizing, it is necessary to remember what is being parenthesized. And it is not the world in general, but the absolute reality which is completely unrelated to my subjective life and my experience. Thus, it is turning towards the reality which is given or which can be given in my experience. The performance of reduction means that the entire reality is returned to its origins, to the structure of the absolutely subjective reality in which the entire reality gains meaning. Philosophical analyses, from the standpoint of Husserl, must inevitably returns to guessing the riddle of transcendental structures of the world and subjectivity.

The concept of reduction has always been criticised for closing oneself in human consciousness and soul after doubting the existence of the real world. However, it appears that such reproaches are baseless, as the reduction returns not to the closed soul, but to funda- 
mental structures of the world and subjectivity enabling the perception of a person as being in the world. The radical reduction gains the inter-subjective nature, as the rejection of the image of consciousness confined in own interiority makes one go deeper into the structures of the transcendental subjectivity in historical, social and cultural dimensions of the world.

\subsection{Third Stage of Husserl's Phenomenology Rational Ethics, Inter-Subjectivity of Mind and Issue of Cultural Life-Worlds}

The third stage of Husserl's phenomenology increasingly emphasises the practical nature of phenomenology, as the issue of life becomes most relevant. It proceeds from logical and epistemological issues to the implementation of phenomenology when solving historical, social and cultural issues. At this stage, the concept of the life-world becomes most important and later widespread in the humanities and social sciences. Husserl's concept of the life-world does not provide ultimate definitions or formulations. Therefore, I am going to interpret the concept of the life-world in order to highlight its relationship with the whole of Husserl's phenomenology and taking into account the main intention of phenomenology. The concept of the life-world does not mean that Husserl refuses the perspective of transcendental philosophy and returns to previously criticised historicism and relativism. On the contrary, Husserl's concept of the life-world provides the new comprehension of historicism and cultural diversity from the perspective of transcendental philosophy.

I would single out three major aspects in the concept of the life-world. First of all, the life-world is understood through the opposition to the scientific world. Secondly, the lifeworld is understood in the context of the phenomenological reduction as the everyday world of direct experience. Thirdly, the life-world is analysed as the expression of intersubjective relations and a priori of historical and cultural differences of life-worlds. Let us examine the opposition between the living world and the scientific world. Scientists usually hold the naive metaphysical belief that theories developed by them are the direct reflection of the objective reality. However, a more careful look at natural sciences reveals that they are based on assumptions which are not considered in those sciences and which are nothing more than obviousness of experience of the living world. According to Husserl, one of the reasons for the crisis of European culture is exactly this prominence given to the objectivity of natural sciences. The modern cognition of the nature isolates itself from everyday experience and devalues it; on the other hand, no science can be significant for a person unless it gets feedback from his/her direct experience. Thus, modern sciences seek to provide the objective image of the world abstracted and isolated from subjective experiences, though, on the other hand, these everyday life experiences are returned to again in order to prove the correctness and significance of these sciences in human life. When perceiving the objective image of the world as the primary reality determining all subjective expressions, the role of scientific practice in creating this image remains unnoticed. The division between the living world and the scientific world enables the critical evaluation of the unilaterality of the perspective of the modern natural science and its relationship with life practices. The scientific practice itself and tools of science belong to the whole of the life-world, therefore, 
they cannot be understood if this life-world is rejected or denied as completely irrelevant to science. The reduction of the scientific image of the world to practices of the life-world reveals the correlation between the scientific world and the life-world. It does not mean that phenomenology seeks to belittle the natural-science, objective cognition through its reduction to dimensions of the everyday world and life experience. Phenomenology rejects not the value of this kind of cognition, but the interpretation of this natural-science cognition, which presents one of the cognition perspective as being the only one right and ultimate. Reflection of the correlation between the scientific world and the life-world reveals not only rooting of science in the actualities of life and its valuable engagement, but also the inverse effect of science on the life-world. It appears that scientific theories are not neutral in respect of our life-world. The metaphysical prominence given to science has the inverse effect on the life-world and changes it. Thus, today we face the situation when the lifeworld is given to us initially permeated with scientific interpretations and technological transformations.

As is obvious from the foregoing, it is important to learn to distinguish between visions of the objective and self-existing world being created by science and how the world is given to me in direct everyday experience. In Husserl's phenomenology, epoche is understood as the act stopping the inert self-assignment to the objective order of the world. In this sense, epoche is the pause allowing to change the standpoint perspective and, instead of relying on the pre-given and self-evident objective order of the world, I must focus on how the world is manifested in my particular experience and how I participate in the creation of meaning of this world with my experience. The positive goal of the phenomenological reduction is to return to experience and to what is given in it, and I can achieve it only by excluding the belief that actualities of the world are objective facts and laws. Thus, instead of the world as it is by itself, I should turn myself towards the world as it is lived. The very name of the life-world indicates that here the world is discovered in the perspective of life experience. If the world is examined without rejecting the practice of life for the sake of the scientific objectivity, then, when turning towards valuable and pragmatic ways of experiencing the world, it appears that the world is not just the scope of natural extended bodies, but the scope of references and meanings. It is this aspect by which the living world is personally oriented towards the world of culture and history. When describing how the life-world is given from the first-person perspective, it appears that the world is experienced as the significant surrounding world whose centre is my body and I. No less important is that this life-world is experienced as the historical world of my present with horizons of the past and future. Eventually, the life-world is not the world experienced by me alone. My experiences also implies the standpoint of others to things of my concern, therefore, experience of the life-world is given not only as egocentric, but also as polycentric.

The third aspect of the life-world is related to the issue of inter-subjectivity. The first question to arise here is the following: is there only one life-world or are there many of them? As mentioned above, the concept of the life-world solves the issue of cultural and historical inter-subjectivity; therefore, I cannot confine myself to the world given to me in the first-person perspective. If my life-world is the only one for me which I can understand 
and accept as mine, then life-worlds of others will always remain alien and incomprehensible for me. When treating the life-world as the cultural world, it is necessary to solve the issue of cultural diversity. Isn't it so that by offering to start the analysis of the life-world from the personally significant world, phenomenology returns us to traps of cultural relativism. Everyone allegedly has their own unique life-world and, therefore, it is impossible to understand the life-world of someone else unless we bring it under the logic of our own life-world. The choice would be as follows: either there are many life-worlds and then everyone lives in his/ her own world unable to understand other life-worlds, or there is one life-world world, but then the cultural diversity does not exist, in other words, it is annexed and brought under the single comprehensive logic, the single value system. Phenomenology offers the transcendental solution: neither the first one, nor the second one, to be more precise, the life-worlds can be very different, though the perception of these differences allows us to presuppose a certain life-world as a priori of historical and cultural worlds. The variation of experience of different cultures, the relevance of different historical eras in the present, extensions of different life-worlds in each other are possible only by a priori of this life-world. It can be stated that the internal cognition of culture does not suffice to explain it, the cognition from the inside as from the outside is required. Only by being able to take the independent position between cultures we can understand both our attribution to a specific cultural tradition and participation in its creation.

It must be noted that at the third stage Husserl experiences the disaster of World War I and the post-war economic and moral crisis. It encouraged to reflect on the background of the crisis of European culture and possibilities for the ethical renewal. A series of articles written by Husserl in 1922-1923 for Japanese magazine «Kaizo» is devoted to these themes. In the first article Husserl formulates his theme as follows:

Something new must happen; something new must happen within us and with our help, as we participate in the humanity living in this world being created from us and creating us from itself. Do we have to wait for the culture to recover by itself, in the accidental play of own forces when values are first created and then destroyed? Do we have to let the "European decline" defeat us as the inevitable fate? This inevitable fate exists only in case we are passive observers, - if we could be passive observers. But it cannot be done even by those declaring us this fate. We are people, subjects who freely express their will, who are actively engaged in the world around us and who are constantly changing it. Whether we want it or not, whether it is good or bad, we act so. Don't we have to act wisely, aren't prudence and efficiency in our power? (Husserl, 1989, 4)

According to Husserl, a person can choose the form of «passive life» which is fully dependent on accidental circumstances and situations. It is life of caring for the self-preservation in the play of accidental determining forces. Such a form of life inherits its goals from the society and traditions, though this passivity is self-deception. Another form of life is the one in which a person himself/herself forms his/her life relying on the ideal of free mind. The rational practice of life is the cultural ideal whose implementation, even though 
it would be the endless goal, should be sought by every individual and society.

Universal changes of the practice must result from the philosophical culture. Husserl relates its discovery to the phenomenon of Ancient Greek philosophy. Therefore, phenomenology is often criticised for excessive Eurocentrism. However, Husserl did not seek to elevate Europe as being superior to other cultures; he merely showed that certain structures appear in this culture, which are also available to all other cultures. Thus, emphasised here are not traditions, customs, but what is universal in the European culture and what, to some extent, negates any particular culture. ${ }^{2}$ This is the rationality which belongs neither to one individual, nor to one culture. Lingis observes:

Foreigners who coming to Greek trading ports were asking the Greeks: "Why do you do that?" In all communities with groups of people cherishing their distinction, the answer used to be and still is: "It is because our fathers taught us this way; it is because our gods told us so". When the Greeks decided to provide the basis acceptable to foreigners who had no Greek fathers and gods, the basis acceptable to any clear mind, - then new things started. (Lingis, 1994, 3).

One of the most important late Husserl's ideas is the relationship between theory and practice. In one of his manuscripts, he states: «The theoretical mind is the theory of the practical mind and it is itself a component of the practically functioning mind». ${ }^{3}$ In «Meditation on the Idea of Absolutely Responsible Individual and Social Life», Husserl formulates a similar idea:

Be that as it may, the cognitive mind is a function of the practical mind, and intellect is the servant of will. But the servant itself performs functions of will, as it is based on cognitive derivatives required to direct the will everywhere, to show it proper goals and path (Husserl, 1959, 201).

The founder of phenomenology emphasises that theories cannot be neutral in respect of human life. The direction specified by theoretical issues has direct consequences for our personal life, as, one way or another, it determines the choice of goals of our life. On the other hand, the way we understand a person determines how we treat him/her. This criticism of objectivistic and naturalistic concepts of a person started by Husserl while criticising the reductionist concept of mind lying in psychologism is also continued in his last book «The Crisis of European Sciences». Here, he emphasises that the theoretical dehumanization of a person becomes the practical destruction of his/her humanity: «Blosse Tatsachenwissenschaften machen blosse Tatsachenmenschen (Merely fact-minded sciences make merely fact-minded people)». ${ }^{4}$

Husserl's criticism of science seeks to reveal how the meaning of human subjectivity and rationality is being gradually forgotten or distorted in history of the modern world,

2 For more details about the issue of Europization in Husserl's phenomenology, see: (Held, 1989, 13-39).

3 Quotation from: (San Martin, 1994, 69).

4 (Husserl, 1954, 4; 1970, 6). 
as the crisis of European existence comes exactly from turning a person and his/her mind into a fact among other facts. Husserl's phenomenology seeks to discover the concept of rationality able to legitimize and give meaning to scientific and ethical activities. However, having started his search from seeking absolutely grounded knowledge, Husserl faces the internal contradiction between phenomenological theory and practice. The latter is overcome only when phenomenology itself turns into the practical self-realization and selfawareness. The meaning of rationality of non-classical phenomenology emerges if the mind is perceived as the mind of life, as the practice in which, on the one hand, the dualism of the world and consciousness is overcome and, on the other hand, consciousness is not reduced to yet another fact of the world.

\section{REFERENCES}

Depraz, N. (2003). Transcendentalinis empirizmas: tarp Husserlio ir Derrida [Transcendental Empiricism: between Husserl and Derrida]. Problemos, (63), 84-95.

Heidegger, M. (2011). History of the Concept of Time. Prolegomena. Bloomington and Indianapolis: Indiana University Press.

Held, K. (1989). Husserls These von der Europäisierung der Menschheit. In Ch. Jamme, \& O. Pöggeler (Eds.), Phänomenologie im Widerstreit (13-39). Frankfurt am Main: Suhrkamp.

Husserl, E. (1959). Erste Philosophie (1923-24). Zweiter Teil: Theorie der phänomenologischen Reduktion. (Hua VIII). Haag: Martinus Nijhoff.

Husserl, E. (1970). The Crisis of European Sciences and Transcendental Phenomenology: an introduction to phenomenological philosophy. Evanston: Nortwestern University Press.

Husserl, E. (1976). Die Krisis der Europäischen Wissenschaften und die transcendentale Phänomenologie. Eine Einleitung in die phänomenologische Philosophie. (Hua VI). Haag: Martinus Nijhoff.

Husserl, E. (1973). Cartesian Meditations. An Introduction to Phenomenology. (Hua I). The Hague: Martinus Nijhoff.

Husserl, E. (1983). Ideas pertaining to a Pure Phenomenology and to a Phenomenological Philosophy. First Book: General Introduction to a Pure Phenomenology. Netherlands: Kluwer.

Husserl, E. (1988). Gesammelte Werke. Aufsätze und Vorträge (1922-1937). (Hua XXVII). Dordrecht: Kluwer.

Lingis, A. (1994). The Community of Those Who Have Nothing in Common. Blomington: Indiana University Press.

Mamardashvili, M. (1993). Kartezianskie razmyshlenija [Cartesian Meditations]. Moscow: Progress. Mickūnas, A., \& Stewart, D. (1990). Exploring Phenomenology. A Guide to the Field and its Literature. Athens: Ohio University Press.

Ortega y Gasset, J. (1961). The Modern Theme. New York: Harper.

San Martin, J. (1987). La structura del metodo fenomenologico. Madrid: UNED.

San Martin, J. (1994). La fenomenologia como teoria de una racionalidad fuerte. Madrid: UNED.

Sodeika, T. (1981). Husserlio fenomenologija [Husserl's Phenomenology]. In Egzistencijos filosofija: istorija ir dabartis [Existential Philosophy: History and Present]. Vilnius: Mintis.

Waldenfels, B. (1999). Fenomenologiya opyta Edmunda Gusserlya [Edmund Husserl's phenomenology of experience]. In A. Mikhailov, \& T. Shchittsova (Eds.), Motiv chuzhogo [Motive of someone else] (15-48). Minsk: Propilei. 